\title{
Determination of Temperature Distribution in a Nuclear Fuel Element Consisting of a Sphere of Fissionable Material and a Spherical Shell of Aluminum Cladding using Finite Element Method
}

\author{
${ }^{1}$ J. A. Akpobi and ${ }^{2}$ G.O Ariavie \\ ${ }^{1}$ Department of Production Engineering, \\ ${ }_{1,2}$ Mechanical Engineering Department, \\ 1,2 University of Benin, Benin City, Edo State, Nigeria. \\ ${ }^{2}$ Federal University of Petroleum Resources, Effurun, Delta State, Nigeria. \\ 1akpobi@uniben.edu, 2ariavie.godfrey@fupre.edu.ng
}

\begin{abstract}
This paper involves the use of Rayleigh-Ritz finite element method to determine the temperature distribution in a nuclear fuel element consisting of a sphere of fissionable material and a spherical shell of aluminum cladding. The differential equation is a one - dimensional second order differential problem. The finite solutions obtained when compared with the exact solutions shows that the accuracy increases as the number of elements increases with decrease in error, and this was shown graphically. It can be stated that finite element method is an accurate method for determining the temperature distribution in a nuclear fuel element consisting of a sphere of fissionable material and a spherical shell of aluminum cladding.
\end{abstract}

Keywords: Rayleigh - Ritz Finite Element method, temperature distribution, nuclear fuel, aluminum cladding.

\section{Introduction}

A nuclear fuel element for use in the core of a nuclear reactor is disclosed and has a composite cladding having a substrate and a metal barrier metallurgically bonded on the inside surface of the substrate so that the metal barrier forms a shield between the substrate and a nuclear fuel material held within the cladding.

A number of researchers have used finite element and other method to study temperature distribution. In recent times, the heat generation due to fission within a nuclear fuel rod is not uniform and for a cylindrical fuel rod, the heat generation is given by [1]. The fuel elements are usually long cylindrical rod or rectangular plates of uranium (or thorium) enclosed by cladding. The uranium may be in the pure metallic form, in the form of a compound such as uranium dioxide $\mathrm{UO}_{2}$ or in the form of an alloy with another metal such as aluminum or zirconium in [2]. Reference [3] analyzed the temperatures and cooling rate that arises during welding. [4] determined temperature distribution on cutting tool in endmilling. ABACUS software based on finite element method was used to study the temperature and heat 
J. A. Akpobi and G.O Ariavie; Determination of Temperature Distribution in a Nuclear Fuel Element Consisting of a Sphere of Fissionable Material and a Spherical Shell of Aluminum Cladding using Finite Element Method, Transactions on Machine Learning and Artificial Intelligence, Volume 2 No 6 Dec, (2014); pp: 17-24

flux changes in a nuclear fuel rod by [5]. Reference [6] proposes to analyze in-pile fission gas release from UO2 fuel. The finite element model describes fission gas transfer from the grain interior to grain boundaries by simultaneous mechanisms of diffusive flow and boundary sweeping considering the effect of irradiation induced resolution when gas amount in grain. [7] used finite element method to determine the temperature distribution on TRISO fuel kernel. In [8] finite element is used to analyze the thermo-structural behaviour of cladding process. Reference [9] used finite element method to solve the problem of stress distribution in a cylindrical nuclear fuel element with a graphite matrix and spherical inclusions. The governing one-dimensional equation for heat transfer in the nuclear fuel element of a fissionable material and aluminum cladding is given in [10].

It is obvious that a number of researchers seem not to have analyzed the temperature distribution in a nuclear fuel element of a spherical form consisting of a sphere of fissionable material surrounded by a spherical shell of aluminum cladding. Hence, this paper using finite element analysis tends to fill this gap.

\section{Methodology}

\subsection{Problem}

Consider a nuclear fuel element of spherical form, consisting of a sphere of "fissionable material surrounded by a spherical shell of aluminum "cladding" as shown in the figure below. Nuclear fission is a source of thermal energy, which varies non-uniformly from the center of the sphere to the interface of the fuel element and the cladding. We wish to determine the temperature distribution in the nuclear fuel element and the aluminum cladding.

The governing equations for the two regions are the same, with the exception that there is no heat source term for the aluminum cladding. We have

$$
\begin{array}{lll}
-\frac{1}{r^{2}} \frac{d}{d r}\left(r^{2} k_{1} \frac{d T_{1}}{d r}\right)=q_{1} & \text { for } & 0 \leq r \leq R f \\
-\frac{1}{r^{2}} \frac{d}{d r}\left(r^{2} k_{2} \frac{d T_{2}}{d r}\right)=0 & \text { for } & R_{f} \leq r \leq R c
\end{array}
$$

Where subscript 1 and 2 refer to the nuclear fuel element and cladding, respectively. The heat generation in the nuclear fuel element is assumed to be of the form

$$
q_{1}=q_{0}\left[1+c\left(\frac{r}{R_{f}}\right)^{2}\right]
$$

Where $q_{0}$ and c are constants depending on the nuclear material. The boundary conditions are;

$$
\begin{gathered}
k r^{2} \frac{d T_{1}}{d r}=0 \quad \text { at } \quad r=0 \\
T_{1}=T_{2} \quad \text { at } \quad r=R_{f}, \quad \text { and } T_{2}=T_{0} \quad \text { at } \quad r=R_{c}
\end{gathered}
$$


Use eight linear elements to determine the finite element solution for the temperature distribution and compare the nodal temperature with the exact solution.

$$
\begin{aligned}
& T_{1}-T_{0}=\frac{q_{0} R_{f}^{2}}{6 k_{1}}\left\{\left[1-\left(\frac{r}{R_{f}}\right)^{2}\right]+\frac{3}{10} c\left[1-\left(\frac{r}{R_{f}}\right)^{4}\right]\right\}+\frac{q_{0} R_{f}^{2}}{3 k_{2}}\left(1+\frac{3}{5} c\right)\left(1-\frac{R_{f}}{R_{c}}\right) \\
& T_{2}-T_{0}=\frac{q_{o} R_{f}^{2}}{3 k_{2}}\left(1+\frac{3}{5} c\right)\left(\frac{R_{f}}{r}-\frac{R_{f}}{R_{c}}\right)
\end{aligned}
$$

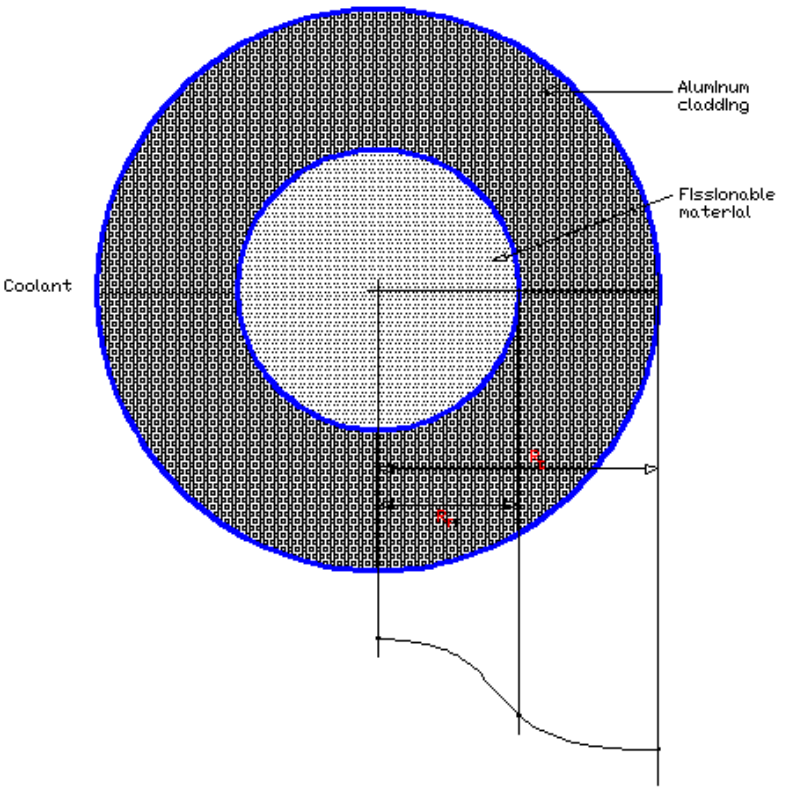

Figure 1: A nuclear fuel elements of spherical form

\subsection{Solution}

Using Rayleigh - Ritz Finite Element method.

Since the problem is a two in one problem, we consider both governing equations separately;

Considering the governing equation of the fissionable material and putting it in residual form as shown below;

$$
-\frac{d}{d r}\left(r^{2} k_{1} \frac{d T_{1}}{d r}\right)=q_{1} r^{2}
$$

we develop the weak form by multiplying through by the weight function (w), equate to zero and then integrate over the whole area. This gives rise to the equation below;

$$
0=2 \pi\left(\int_{r_{a}}^{h+r_{a}} \frac{d w}{d r} r^{2} k_{1} \frac{d T_{1}}{d r}-q_{1} w r^{2}\right) d r-\left.\left(2 \pi w k_{1} r^{2} \frac{d T_{1}}{d r}\right)\right|_{r_{a}} h+r_{a}
$$

The general weak form for this fissionable material is therefore written as; 


$$
0=\left(\int_{r_{a}}^{h+r_{a}} \frac{d w}{d r} r^{2} k_{1} \frac{d T_{1}}{d r}-q_{1} w r^{2}\right) d r-\left.\left(w k_{1} r^{2} \frac{d T_{1}}{d r}\right)\right|_{r_{a}} ^{h+r_{a}}
$$

Considering the governing equation of the Aluminum Cladding and putting it in residual form as shown below;

$$
-\frac{d}{d r}\left(r^{2} k_{2} \frac{d T_{2}}{d r}\right)=0 r^{2}
$$

we develop the weak form by multiplying through by the weight function (w), equate to zero and then integrate over the whole area. This gives rise to the equation below;

$$
0=2 \pi\left(\int_{r_{a}}^{h+r_{a}} \frac{d w}{d r} r^{2} k_{2} \frac{d T_{2}}{d r}\right) d r-\left.\left(2 \pi w k_{2} r^{2} \frac{d T_{2}}{d r}\right)\right|_{r_{a}} ^{h+r_{a}}
$$

Where $\left(r_{a}, h+r_{a}\right)$ is the domain of the element along its radius.

Since there is no heat loss, the weak form for the Aluminum Cladding is therefore written as;

$$
0=\left(\int_{r_{a}}^{h+r_{a}} \frac{d w}{d r} r^{2} k_{2} \frac{d T_{2}}{d r}\right) d r-\left.\left(w k_{2} r^{2} \frac{d T_{2}}{d r}\right)\right|_{r_{a}} ^{h+r_{a}}
$$

The approximate solution is of the form;

$$
T(r)=\sum_{j=1}^{n} T_{i}^{e} \psi_{j}^{e}(r)
$$

Where

$$
\sum_{j=1}^{n} T_{i}^{e} \psi_{j}^{e}(r)=T_{1}^{e} \psi_{1}^{e}+T_{2}^{e} \psi_{2}^{e}+T_{3}^{e} \psi_{3}^{e}+\ldots+T_{n}^{e} \psi_{n}^{e}(r)
$$

\subsubsection{For the Fissionable material}

Substituting equation (14) into the weak form of the fissionable material, and w for $\psi$ (for $i=1$ to 3 ), we have;

$$
0=\int_{r_{a}}^{h+r_{a}}\left(r^{2} k_{1} \frac{d \psi_{i}}{d r}\left(\sum_{j=1}^{3} T_{i}^{e} \frac{d \psi_{i}}{d r}\right)-q_{1} \omega r^{2}\right) d r-\sum_{j=1}^{3} \psi_{i}^{e} Q_{j}^{e}(r)
$$

The above can be written in the form;

$$
\sum_{j=1}^{n} k_{i j} w_{j}^{e}=f_{i}+Q_{i}^{e}
$$

The finite element model can therefore be represented as; 


$$
k_{i j}=f_{i}^{e}+Q_{i}^{e}
$$

Where

$$
k_{i j}=\int_{r_{a}}^{h+r_{a}}\left(r^{2} k_{1} \frac{d \psi_{i}}{d r} \cdot \frac{d \psi_{j}}{d r}\right) d r
$$

And

$$
f_{i}^{e}=\int_{r_{a}}^{h+r_{a}} q_{1} \psi_{i} r^{2} d r
$$

\subsubsection{For Aluminium Cladding;}

Substituting equation (14) into the weak form of the aluminium cladding, and w for $\psi$ (for $i=1$ to 3 ), we have;

$$
0=\int_{r_{a}}^{h+r_{a}}\left(r^{2} k_{2} \frac{d \psi_{i}}{d r}\left(\sum_{j=1}^{3} T_{i}^{e} \frac{d \psi_{i}}{d r}\right)\right) d r-\sum_{j=1}^{3} \psi_{i}^{e} Q_{j}^{e}(r)
$$

The above can be written in the form;

$$
\sum_{j=1}^{n} k_{i j} w_{j}^{e}=f_{i}+Q_{i}^{e}
$$

The finite element model can therefore be represented as;

$$
\begin{gathered}
k_{i j}=f_{i}^{e}+Q_{i}^{e} \\
\text { Where } k_{i j}=\int_{r_{a}}^{h+r_{a}}\left(r^{2} k_{2} \frac{d \psi_{i}}{d r} \cdot \frac{d \psi_{j}}{d r}\right) d r \\
\text { And } f_{i}^{e}=0
\end{gathered}
$$

Evaluating the coefficient matrix using MathCAD software, results are obtained for $k_{1}$ and $k_{2}$. The matrix obtained is thus;

$$
\begin{gathered}
k_{i j}=\frac{k}{15 h}\left(\begin{array}{ccc}
3 h^{2}+15 h r a+35 r a^{2} & -\left(6 h^{2}+20 h r a+40 r a^{2}\right) & 3 h^{2}+5 h r a+5 r a^{2} \\
-\left(6 h^{2}+20 h r a+40 r a^{2}\right) & 32 h^{2}+80 h r a+80 r a^{2} & -\left(26 h^{2}+60 h r a+40 r a^{2}\right) \\
3 h^{2}+5 h r a+5 r a^{2} & -\left(26 h^{2}+60 h r a+40 r a^{2}\right) & 23 h^{2}+55 h r a+35 r a^{2}
\end{array}\right) \\
f_{i}=\frac{q_{1} h}{15}\left(\begin{array}{c}
\frac{\left(h^{2}+10 r a^{2}\right)}{4} \\
3 h^{2}+10 h r a+10 r a^{2} \\
\frac{\left(9 h^{2}+20 h r a+10 r a^{2}\right)}{4}
\end{array}\right)
\end{gathered}
$$


J. A. Akpobi and G.O Ariavie; Determination of Temperature Distribution in a Nuclear Fuel Element Consisting of a Sphere of Fissionable Material and a Spherical Shell of Aluminum Cladding using Finite Element Method, Transactions on Machine Learning and Artificial Intelligence, Volume 2 No 6 Dec, (2014); pp: 17-24

Where we have $k$, we substitute into it, $k_{1}$ and $k_{2}$ which are used in solving the equations of fissionable material and aluminum cladding respectively.

\subsection{Assembly of the Matrix Using Eight Elements}

Next, we assemble the matrix using eight elements with four elements each for the fissionable material and Aluminium Cladding, since they both share the same centre, thereafter; we mesh the elements to get a $17 \times 17$ matrix.

An illustration using one element each is shown below;

For fissionable material;

$$
\left(\begin{array}{lll}
k_{11}^{1} & k_{12}^{1} & k_{13}^{1} \\
k_{21}^{1} & k_{22}^{1} & k_{23}^{1} \\
k_{31}^{1} & k_{32}^{1} & k_{33}^{1}
\end{array}\right)\left(\begin{array}{l}
T_{1}^{1} \\
T_{2}^{1} \\
T_{3}^{1}
\end{array}\right)=\left(\begin{array}{l}
Q_{1}^{1} \\
Q_{2}^{1} \\
Q_{3}^{1}
\end{array}\right)
$$

For Aluminium Cladding;

$$
\left(\begin{array}{lll}
k_{11}^{2} & k_{12}^{2} & k_{13}^{2} \\
k_{21}^{2} & k_{22}^{2} & k_{23}^{2} \\
k_{31}^{2} & k_{32}^{2} & k_{33}^{2}
\end{array}\right)\left(\begin{array}{l}
T_{1}^{2} \\
T_{2}^{2} \\
T_{3}^{2}
\end{array}\right)=\left(\begin{array}{l}
Q_{1}^{1} \\
Q_{2}^{1} \\
Q_{3}^{1}
\end{array}\right)
$$

From boundary condition,

$$
T_{1}=T_{2} \text { at } r=R_{F} \text { and } T_{2}=T_{0} \text { at } r=R_{c}
$$

The mesh becomes;

$$
\left[\begin{array}{ccccc}
k_{11}^{1} & k_{12}^{1} & k_{13}^{1} & 0 & 0 \\
k_{21}^{1} & k_{22}^{1} & k_{23}^{1} & 0 & 0 \\
k_{31}^{1} & k_{32}^{1} & k_{33}^{1}+k_{11}^{2} & k_{12}^{2} & k_{13}^{2} \\
0 & 0 & k_{21}^{2} & k_{22}^{2} & k_{23}^{2} \\
0 & 0 & k_{31}^{2} & k_{32}^{2} & k_{33}^{2}
\end{array}\right]\left[\begin{array}{c}
T_{1} \\
T_{2} \\
T_{3} \\
T_{4} \\
T_{5}
\end{array}\right]=\left[\begin{array}{c}
Q_{1}^{1} \\
Q_{2}^{1} \\
Q_{3}^{1}+Q_{1}^{2} \\
Q_{2}^{2} \\
Q_{3}^{2}
\end{array}\right]
$$

The eight element mesh follows the same procedure.

\section{Results}

The results obtained from the finite element method are compared to that of the exact solutions.

Assuming that; $k_{1}=25 \mathrm{~m}^{3} / \mathrm{h}, k_{2}=20 \mathrm{~m}^{3} / \mathrm{h}, R_{F}=8 \mathrm{~m}, R_{c}=16 \mathrm{~m}, q_{1}=30 \mathrm{~m}^{3} / \mathrm{h}$, $q_{0}=11.5385 \mathrm{~m}^{3} / \mathrm{h}, c=0.4, T_{o}=20^{0} \mathrm{C}, h=\frac{L}{n}=\frac{8}{4}=2$.

Four elements each are used for the fissionable material and the aluminum cladding. The fourth element of the fissionable material is merged with the first element of the aluminum cladding material 
to get a total of eight elements. The finite solution is determined after the boundary conditions have been applied. The results are shown in the table below;

Table 1: Values of Exact and Finite Element Method Solutions for Temperatures of Nuclear Fuel for Eight Elements

\begin{tabular}{|c|c|c|c|c|c|}
\hline RADIUS & FEA SOLUTIONS & EXACT SOLUTIONS & ERROR & $\begin{array}{c}\text { PERCENTAGE } \\
\text { ERROR (\%) }\end{array}$ & $\begin{array}{c}\text { ACCURACY } \\
\text { (\%) }\end{array}$ \\
\hline 0 & 42.9813 & 33.14464342 & 0.22885898 & 22.885898 & 77.114102 \\
\hline 1 & 41.7413 & 33.06757595 & 0.20779717 & 20.779717 & 79.220283 \\
\hline 2 & 40.9013 & 32.83464276 & 0.19722251 & 19.722251 & 80.277749 \\
\hline 3 & 40.3169 & 32.44065154 & 0.19535848 & 19.535848 & 80.464152 \\
\hline 4 & 39.1347 & 31.87694841 & 0.18545566 & 18.545565 & 81.454435 \\
\hline 5 & 38.0828 & 31.13141797 & 0.18253338 & 18.253338 & 81.746662 \\
\hline 6 & 36.3864 & 30.18848327 & 0.17033608 & 17.033608 & 82.966392 \\
\hline 7 & 34.8207 & 29.0291058 & 0.16632619 & 16.632619 & 83.367381 \\
\hline 8 & 32.5991 & 27.63078551 & 0.15240649 & 15.240649 & 84.759351 \\
\hline 9 & 29.8015 & 25.93505539 & 0.12973993 & 12.973993 & 87.026007 \\
\hline 10 & 27.5597 & 24.5784713 & 0.10817348 & 10.817348 & 89.182652 \\
\hline 11 & 25.7278 & 23.46853887 & 0.08781400 & 08.781400 & 91.218600 \\
\hline 12 & 24.1999 & 22.54359517 & 0.06844263 & 06.844263 & 93.155737 \\
\hline 13 & 22.9080 & 21.76095050 & 0.05007201 & 05.007201 & 94.992799 \\
\hline 14 & 21.8000 & 21.09011222 & 0.03256366 & 03.256366 & 96.743634 \\
\hline 15 & 20.8401 & 20.50871903 & 0.01590112 & 01.590112 & 98.409888 \\
\hline 16 & 20.0000 & 20.00000000 & 0.00000000 & 00.000000 & 100.000000 \\
\hline & & & & & \\
\hline
\end{tabular}

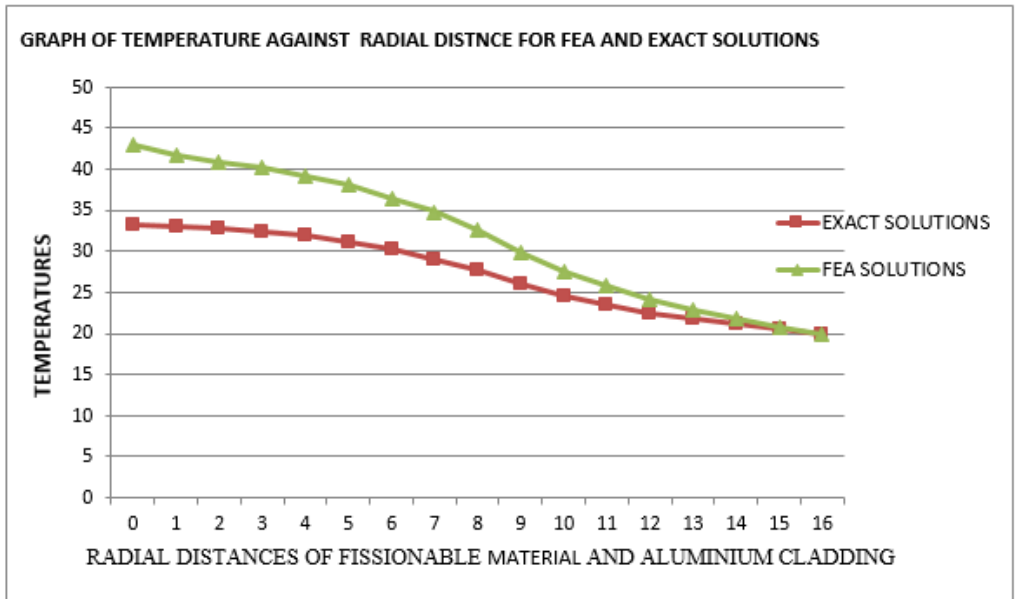

Figure 2: Graph of Temperature against Radial Distance for FEA and Exact Solutions

\section{Discussion}

The Finite Element solutions obtained in the problem can be used to determine the distribution of temperature distribution in a nuclear fuel element consisting of a sphere of fissionable material and a spherical shell of aluminum cladding. This is as a result of substituting the appropriate values of the domains and boundary conditions into the formulated coefficient matrix equations. The results are represented in the table, and it shows that there is increase in accuracy as the number of element 
J. A. Akpobi and G.O Ariavie; Determination of Temperature Distribution in a Nuclear Fuel Element Consisting of a Sphere of Fissionable Material and a Spherical Shell of Aluminum Cladding using Finite Element Method, Transactions on Machine Learning and Artificial Intelligence, Volume 2 No 6 Dec, (2014); pp: 17-24

increases with decrease in error. The graph of the finite element solutions and the exact solutions has separate paths but converges at a point.

\section{Conclusion}

The results shows that finite element method is a more reliable and accurate method for determining the temperature distribution in a nuclear fuel element consisting of a sphere of fissionable material and a spherical shell of aluminum cladding successfully.

\section{REFERENCES}

[1]. Pandey, K.M and Mahesh, M. (2010), "Determination of temperature distribution in a cylinder nuclear Fuel Rod", a Mathematical Approach. International Journal of Innovation, Management and Technology. Volume 1, no. 5.

[2]. Gupta, G.P. and Rajendra Prakash (1994), "Engineering Heat Transfer", Nemchand and Brothers, $6^{\text {th }}$ Edition.

[3]. Elijah, Kannatey - Asibu, Jri, Jalld A.R and Noboru, K.(1989),"Journal of engineering materials and technology", vol. 11.

[4]. Noor, M. M., Kadirgama, Rahman, M.M, Harun, W.S.M and Haron, C.H.C (2009),"Finite Elwment Analysis and Statistical Method to determine temperature distribution of cutting tool in EndMilling.

[5]. Eskandari. M.R, Bavandi and Mihandoost (2012), "Studies on Nuclear Fuel Rod Thermal Performance".

[6]. Kenichi ITO, Ryo Iwasaki and Yoshihiko Iwano (1984), "Finite Element Model for Analysis of Fission gas Release from uranium dioxide fuel", pp $129-138$.

[7]. Saragi E. (2012), "Modelling of Temperature distribution in TRISO fuel based on Finite Element Method", vol. 1448, pp 270.

[8]. Purohit, G.K and Kalakesh Baligar (2012), "Cladding Process Simulation And Residual Stress Estimation Using Finite Element Coupled Field Analysis". International Journal of Engineering Research and Technology. Vol 1, ISSN $2278-0181$.

[9]. Isakor, V., Zaznoba, V., and Konopler, E. (2006), "Theoritical Foundation of Chemical Engineering", Volume 40, pp 431.

[10]. Reddy, J. N (1984), "An introduction to Finite Element Method", Texas, McGraw Hill Second Edition. 